\title{
Low APGAR Score as a Risk Factor for Retinopathy of Prematurity
}

\author{
Alok Ranjan'1 Jayati Pandey², Jeevan Singh Mapwal’3, Perwez Khan4 \\ ${ }^{1}$ Department of Ophthalmology, GSVM Medical College, Kanpur, Uttar Pradesh, India. ${ }^{2}$ Department of Ophthalmology, \\ GSVM Medical College, Kanpur, Uttar Pradesh, India. ${ }^{3}$ Department of Ophthalmology, GSVM Medical College, Kanpur, \\ Uttar Pradesh, India. ${ }^{4}$ Department of Ophthalmology, GSVM Medical College, Kanpur, Uttar Pradesh, India.
}

\section{ABSTRACT}

\section{BACKGROUND}

ROP is a vasoproliferative disease which affects the developing retinal blood vessels of premature infants. The spectrum of ROP range from minimal sequelae, which do not affect vision to bilateral Retinal Detachment (RD) and total blindness. APGAR score (Appearance, Pulse, Grimace, Activity and Respiration) provides an accepted and convenient method for reporting the status of the newborn immediately after birth and the response to resuscitation if needed. The test is generally done 1 and 5 minutes after birth and may be repeated later if the score is and remains low. Scores 7 and above are generally normal, 4 to 6 fairly low and 3 and below are generally regarded as critically low. A low score at 1 minute may show that the neonates require medical attention but does not necessarily indicate a long-term problem, particularly if score improves at 5 minutes. Currently the most important risk factors for development of ROP are gestational age and birth weight. APGAR score is a routinely used index in neonatology; thus, it makes it easier for a neonatologist to select neonates who should be sent for ROP screening. We wanted to determine the relationship of APGAR score and Retinopathy of Prematurity (ROP).

\section{METHODS}

APGAR Score at 1 minute and 5 minutes of 107 newborns of low gestational age ( $<32$ weeks) were evaluated. Their fundus examination was done using indirect ophthalmoscope to screen for ROP.

\section{RESULTS}

Out of 107 neonates, $23.36 \%$ of neonates were found to have ROP. Significantly lower APGAR score at 1 minute $(\mathrm{p}<0.0001)$ as well as at 5 minutes $(\mathrm{p}<0.0001)$ was found in ROP cases. The association of ROP was strongly seen with APGAR score at 1 minute $\left(r^{2}=0.81\right)$ than at 5 minutes $\left(r^{2}=0.61\right)$.

\section{CONCLUSIONS}

Low APGAR score at 1 minute and 5 minutes is significantly associated with ROP. So, recording of Apgar score and providing resuscitation measures should be done for every premature infant. Neonates with low Apgar score should be screened for ROP so that timely intervention can be done.

\section{KEY WORDS}

Apgar Score, Retinopathy of Prematurity

\author{
Corresponding Author: \\ Dr. Alok Ranjan, \\ P. G. Boys Hostel, \\ GSVM Medical College, \\ Swaroop Nagar, Kanpur, \\ Uttar Pradesh, India. \\ E-mail: dr.alok14@gmail.com
}

DOI: $10.14260 / j e m d s / 2019 / 817$

Financial or Other Competing Interests: None.

How to Cite This Article:

Ranjan A, Pandey J, Mapwal JS, et al. Low APGAR score as a risk factor for retinopathy of prematurity. J. Evolution Med. Dent. Sci. 2019;8(50):3772-3774, DOI: $10.14260 / j e m d s / 2019 / 817$

Submission 21-09-2019,

Peer Review 19-11-2019,

Acceptance 05-12-2019,

Published 16-12-2019. 


\section{BACKGROUND}

ROP is a vasoproliferative disease which affects the developing retinal blood vessels of premature infants. The spectrum of ROP range from minimal sequelae, which do not affect vision to bilateral Retinal Detachment (RD) and total blindness. Advances in neonatology and improvement in health care have resulted in increasing number of premature and Extremely Low Birth Weight (ELBW) babies surviving the neonatal period leading to increase of developing ROP. ROP is a leading cause of blindness in children (1) and accounts for up to $10 \%$ of childhood blindness worldwide.(2) The stages of ROP are classified according to recommendation summarised in the International Classification of ROP first published in 1985 and later in 2005.(3)

There are 5 stages which describe the abnormal vascular response at the junction of the vascularised and avascular retina- Stage 1- Demarcation Line- It's a definite structure that separates the avascular retina anteriorly from the vascularised retina posteriorly. Stage 2- It arises in the region of the demarcation line, has height and width and extends above the plane of the retina. Stage 3- Extra retinal fibrovascular proliferation - Neovascularisation extends from the ridge into the vitreous. Stage 4- Partial Retinal detachment - Divided into extrafoveal (Stage 4A) and foveal (Stage 4B) partial retinal detachments. Stage 5- Retinal detachments are generally tractional.

In the majority of infants, ROP is a mild disease and undergoes spontaneous regression with no significant visual sequelae. However, in a significant number of cases progression to advanced ROP occurs resulting in severe visual impairment.

\section{APGAR Score}

APGAR score (Appearance, Pulse, Grimace, Activity and Respiration) provides an accepted and convenient method for reporting the status of the newborn immediately after birth and the response to resuscitation if needed. The test is generally done 1 and 5 minutes after birth and may be repeated later if the score is and remains low. Scores 7 and above are generally normal, 4 to 6 fairly low and 3 and below are generally regarded as critically low. A low score at 1 minute may require medical attention but does not necessarily indicate a long-term problem, particularly if score improves at 5 minutes.

We wanted to determine the relationship of APGAR score and ROP.

\section{METHODS}

It is a hospital based cross-sectional study. 107 patients presented to retina unit of ophthalmology department from January 2016 to December 2016 were evaluated. APGAR score of the newborns of was also evaluated. Premature infants born at home or in other hospital transferred after birth was excluded. Newborns with major congenital anomalies or anomalies preventing good fundus assessment were also excluded. Fundus examination was performed between 3-4 weeks of postnatal age after pupillary dilatation with $2.5 \%$ phenylephrine and $0.5 \%$ Tropicamide eye drops using indirect ophthalmoscope and 20D lens with neonatal speculum. Screening was done according to criteria laid down by the American Academy of Paediatrics and Ophthalmology. APGAR at 1 minute and 5 minutes was recorded for each study participant.

\section{Screening}

- The Revised Joint Policy Statement issued in 2013 by the American Academy of Pediatrics, the American Association of Pediatric Ophthalmology and Strabismus, and the American Academy of Ophthalmology provides guidelines on screening and follow-up of premature neonates (Table 2).

- Indications for screening are region dependent. Those in Table 2 are guidelines by American physicians.

- In the United States premature neonates are examined for ROP if they have a birth weight of less than or equal to 1500 $\mathrm{g}$ or a gestational age of 30 weeks or less. Select infants with a birth weight between $1500 \mathrm{~g}$ and $2000 \mathrm{~g}$ or a gestational age at birth of greater than 30 weeks with an unstable clinical course should also have an eye exam.

\begin{tabular}{|c|c|}
\hline $\begin{array}{c}\text { Screening } \\
\text { Interval }\end{array}$ & Disease Features \\
\hline $\begin{array}{c}\text { 1 week or less } \\
\text { follow-up }\end{array}$ & $\bullet$ Zone I retinal vessels ending without ROP, stage 1 or 2 ROP \\
& $\bullet$ Zone II, Stage 2 or 3 ROP \\
\hline $\begin{array}{c}\text { 1 to 2-week follow- } \\
\text { up }\end{array}$ & $\bullet$ Zone I, regressing ROP \\
\hline 2-week follow-up & $\bullet$ Zone II, Stage 1 ROP II, Stage 1 or regressing ROP \\
\hline $\begin{array}{c}\text { 2 to 3-week follow- } \\
\text { up }\end{array}$ & $\bullet \begin{array}{l}\text { Zone II, immature vascularization without ROP. Zone III, } \\
\text { Stage 1 or 2 or regressing ROP }\end{array}$ \\
\hline \multicolumn{2}{|c|}{ Screening Guidelines for Retinopathy of Prematurity } \\
\hline \multicolumn{2}{|c}{}
\end{tabular}

\section{Statistical Analysis}

Continuous data were presented as mean with a standard deviation. To compare continuous data, unpaired t test was used. For categorical data, Fischer's exact test was applied. Correlation coefficient was calculated to measure strength of association of APGAR score with ROP. Statistical significance was set at $\mathrm{p}<0.05$

\section{RESULTS}

\begin{tabular}{|c|c|c|}
\hline & ROP Present & ROP Absent \\
\hline Number of Neonates & 25 & 82 \\
\hline Mean APGAR Score & $4.16 \pm 0.473$ & $6.48 \pm 0.71$ \\
\hline \multicolumn{2}{|c|}{ Table 1. Mean APGAR Score in Neonates 1 Minute } \\
\hline
\end{tabular}

\begin{tabular}{|c|c|c|}
\hline & ROP Present & ROP Absent \\
\hline Number of Neonates & 25 & 82 \\
\hline Mean APGAR Score & $5.52 \pm 1.0$ & $7.01 \pm 0.76$ \\
\hline \multicolumn{2}{|c|}{ Table 2. Mean APGAR Score in Neonates 5 Minutes } \\
\hline
\end{tabular}

Out of 107 newborns screened ROP was found in 25 neonates who had mean APGAR score of $4.16 \pm 0.47$ at 1 minute and $5.52 \pm 1.0$ at 5 minutes. In 82 neonates no ROP was found and their mean APGAR score was $6.48 \pm 0.71$ at 1 minute and $7.01 \pm 0.76$ at 5 minutes. 


\section{DISCUSSION}

Currently the most important risk factors for development of ROP are gestational age and birth weight. $(4,5)$ Out of 107 premature infants screened incidence of ROP was found to be $23.36 \%$. There is variable incidence of ROP reported in various studies ranging from 11-52\%,6,7) depending upon the hospital facilities to provide postnatal care to the newborns resulting in different survival rates in different setups. It also depends upon the awareness for screening of ROP at different places. In our study ROP cases had significantly lower APGAR at 1 minute $(\mathrm{p}<0.0001)$ as well as 5 minutes $(\mathrm{p}<0.0001)$ as compared to the neonates not having ROP. The association of ROP was more strongly seen with APGAR at 1 minute $\left(\mathrm{r}^{2}=0.81\right)$ than APGAR at 5 minutes $\left(r^{2}=0.61\right)$. Similar to ours Alajbejovic J. et al (8) in their study found out that low APGAR at 1 minute $(3.20 \pm 1.30)$ and 5 minutes $(5.20 \pm 1.09)$ were significantly associated $(\mathrm{p}=0.002$; $\mathrm{p}=0.001$ respectively) with occurrence of ROP. Also, study conducted by Chirico G et al (9) the association of ROP was significantly associated with low APGAR score at 1 minute and 5 minutes $(\mathrm{p}<0.001 ; \mathrm{p}<0.0001$ respectively). GarciaSerrano et al examined different risk factors for development of plus disease among prematurely born multiplets and found low APGAR score at 5 minutes to be a significant and independent risk factor (10). However, in a study conducted by Arne M. et al, low APGAR score at 1 minute $(\mathrm{p}<0.0001)$ was significantly associated with occurrence of ROP.(11) Though APGAR at 5 minutes $(p=0.05)$ was not quite significant associated but was positively associated with the occurrence of ROP.

\section{CONCLUSIONS}

Improved health care and advances in neonatology has led to survival of more and more prematurely born infants. This has led to the necessity of finding non-invasive prognostic factors to identify patients who need interventions in time. This will reduce unnecessary ophthalmological examination of newborns which is a cumbersome procedure and also reducing risk of infections to newborn without missing patients at risk. APGAR score is routinely used index in neonatology thus it makes it easier for a neonatologist to select neonates who should be sent for ROP screening. APGAR score at 1 minute and 5 minutes has proved to be an important factor for predicting ROP and its progression and hence can facilitate in following patients who need treatment.

\section{REFERENCES}

[1] Nissenkorn I, Wijsenbeek Y, Cohen S, et al. Etiology of blindness in children in Israel in recent years. Acta Concilium Ophthalmologicum 1987;25:742-4.

[2] Goggin M, O'Keefe M. Childhood blindness in the Republic of Ireland: a national survey. Br J Ophthalmol 1991;75(7):425-9.

[3] International Committee for the Classification of Retinopathy of Prematurity. The international classification of retinopathy of prematurity revisited. Arch Ophthalmol 2005;123(7):991-9.

[4] Gilbert C. Retinopathy of prematurity: a global perspective of the epidemics, population of babies at risk and implications for control. Early Hum Dev 2008;84(2):77-82.

[5] Gilbert C, Fielder A, Gordillo L, et al. Characteristics of infants with severe retinopathy of prematurity in countries with low, moderate and high levels of development: implications for screening programs. Pediatrics 2005;115(5):e518-e25.

[6] Varughese S, Jain S, Gupta N, et al. Magnitude of the problem of retinopathy of prematurity. Experience in a large maternity unit with a medium size level-3 nursery. Indian J Ophthalmol 2001;49(3):187-8.

[7] Shah VA, Yeo CL, Ling YL, et al. Incidence, risk factors of retinopathy of prematurity among very low birth weight infants in Singapore. Am Acad Med Singapore 2005;34(2):169-78.

[8] Alajbegovic-Halimic J, Zvizdic D, Alimanovic-Halilovic E, et al. Risk factors for retinopathy of prematurity in premature born children. Med Arch 2015;69(6):409-13.

[9] Chrico G. Italian multicentre study on retinopathy of prematurity. The Italian retinopathy of prematurity Study Group. Eur J Pediatr 1997;156(12):939-43.

[10] Garcia-Serrano JL, Ramriez-Garcia MC, Pinar-Molina R. Retinopathy of prematurity in multiple births: risk analysis for plus disease. Arch Soc Esp Ophthalmol 2009;84(4):191-8.

[11] Arroe M, Peitersen B. Retinopathy of prematurity: review of seven-year period in a Danish neonatal intensive care unit. Acta Pediatr 1994;83(5):501-5. 